\title{
MEDIAÇÃO NA RESOLUÇÃO DE CONFLITOS EMPRESARIAIS
}

\section{ARTIGO ORIGINAL}

SOUZA, Jaqueline Caldeira ${ }^{1}$, TARTUCE, Fernanda ${ }^{2}$

SOUZA, Jaqueline Caldeira. TARTUCE, Fernanda. Mediação na resolução de conflitos empresariais. Revista Científica Multidisciplinar Núcleo do Conhecimento. Ano. 06, Ed. 12, Vol. 06, pp. 166-188. Dezembro de 2021. ISSN: 2448-0959, Link de acesso: https://www.nucleodoconhecimento.com.br/lei/resolucao-de-conflitos, DOI: 10.32749/nucleodoconhecimento.com.br/lei/resolucao-de-conflitos

\section{RESUMO}

O objetivo deste artigo é analisar a aplicabilidade da mediação como método adequado de resolução de conflitos empresariais, buscando demonstrar os benefícios que sua utilização pode proporcionar na resolução de controvérsias e no restabelecimento da comunicação entre as partes, com soluções mais céleres, criativas, sigilosas e eficazes. Desta forma, o presente trabalho tem como questão norteadora: A mediação como método de solução consensual, seria adequada e benéfica para resolver conflitos empresariais? Sendo traçada uma breve análise dos métodos adequados de soluções de conflitos e as suas principais diferenças, bem como uma ampla visão sobre a mediação extrajudicial e suas particularidades, abordando sua relação e aplicação no âmbito empresarial, apresentando algumas experiências bem-sucedidas, que comprovam a eficácia e os benefícios do procedimento, servindo de incentivo ao uso da mediação empresarial. Este método de solução de conflitos tem adquirido grandes proporções nas mais diversas áreas do Direito, face à crise judicial vivenciada pela sociedade contemporânea, bem como a crescente procura por métodos que atendam às necessidades dos conflitos, que se tornam cada vez mais complexos, abrindo espaço para o desenvolvimento dos métodos adequados de solução de conflitos, tais como conciliação, mediação,

\footnotetext{
${ }^{1}$ Mestranda em Direito, Pós-Graduada em Direito Processual Aplicado, Bacharel em Direito.

${ }^{2}$ Orientadora.
} 
negociação e arbitragem. A mediação em particular, tem se mostrado apta na resolução de conflitos empresariais, embora existam alguns desafios a serem enfrentados, visto que grande parte do empresariado do país ainda não cogita em recorrer à mediação, seja por dúvida na utilização do método ou o desconhecimento dos seus benefícios. Porém, algumas experiências com resultados positivos comprovam que a mediação é adequada para solução de conflitos e preservação das relações empresariais. O método de investigação utilizado foi o hipotéticodedutivo, considerando conceitos teóricos, análise empírica e pesquisa bibliográfica, conclui-se que a mediação extrajudicial é aplicável, adequada e benéfica na resolução de conflitos empresariais, com custos baixos, maior celeridade, procedimento simplificado, mediadores qualificados, todos os atos sigilosos, e a contemplação dos interesses das partes, com soluções criativas e maior probabilidade do adimplemento do termo final.

Palavras-chave: Mediação Privada, Conflitos Empresariais, Solução Consensual.

\section{INTRODUÇÃO}

Com a evolução tecnológica, dos meios de comunicação, com o desenvolvimento da sociedade, e a transformação dos aspectos econômicos e concorrenciais, as empresas são obrigadas a serem mais dinâmicas no gerenciamento e na resolução de seus conflitos, pois este senário exige respostas rápidas e eficazes.

$\mathrm{Na}$ sociedade contemporânea em meio às transformações e às crises econômicas, as empresas estão suscetíveis a inúmeras disputas, cada vez mais complexas, fazendo com que a busca por soluções mais eficazes se torne mais frequente, a busca por métodos que possam contribuir com a preservação e a imagem da empresa, e evitar prejuízos econômicos.

Os conflitos empresariais sem a devida gestão podem deixar grandes reflexos, atrasando o desenvolvimento da empresa. A mediação pode ser uma ótima ferramenta no gerenciamento desses conflitos, visto que as estratégias e métodos utilizados na mediação podem proporcionar acordos mais eficazes, sigilosos, com 
ganho mútuo, poupando tempo e recursos financeiros, preservando a autonomia e as relações entre as partes. Diante desse contexto para delimitação do tema optouse pelo seguinte problema: A mediação como método de solução consensual, seria adequada e benéfica para resolver conflitos empresariais?

O papel da mediação é restabelecer a comunicação entre os envolvidos, em um senário informal, possibilitando às partes escolherem o mediador, assumirem a responsabilidade da solução da controvérsia que Ihes aflige, formando um consenso em relação ao termo ajustado e proporcionando seu cumprimento espontâneo.

Com a Resolução 125/2010 do Conselho Nacional de Justiça, houve um incentivo ao uso de formas autocompositivas, onde o Estado disponibiliza a sociedade meios alternativos para solucionar seus conflitos, principalmente por meios consensuais, visando a pacificação social. (BRASIL, 2010)

Os métodos adequados de solução de conflitos, embora semelhantes, diferem entre si, pois cada instituto possui suas peculiaridades, com mecanismos diferenciados que se adéquam aos conflitos que lhe serão apresentados, garantindo uma solução mais efetiva.

A mediação extrajudicial em específico, como método adequado de resolução de conflitos empresariais, traz as vantagens no âmbito empresarial e contribui para o crescimento e a preservação da empresa e de suas relações comerciais.

Nesse contexto, o presente estudo parte da hipótese de que a mediação empresarial é aplicável e adequada a resolver de forma efetiva os conflitos empresariais. Partindo da investigação e análise textual, de doutrinas, legislações pertinentes e de algumas experiências já realizadas na resolução de conflitos empresariais, buscando aprimorar o conhecimento sobre o assunto, estimulando e incentivando o desenvolvimento de soluções consensuais.

Adota-se no presente estudo o método hipotético-dedutivo, juntamente com a pesquisa bibliográfica e legislativa. 


\section{MÉTODOS ADEQUADOS DE SOLUÇÃO DE DISPUTAS}

Com o aumento de conflitos cada vez mais complexos, devido às mudanças nas relações, uso de redes virtuais, recursos tecnológicos cada vez mais sofisticados e a insatisfação das partes com o sistema de jurisdição estatal, gera a decadência do monopólio jurisdicional, aumentando assim, a busca por meios adequados de resolução de conflitos (SILVA, 2019).

Embora a ciência jurídica tenha como base a lei, a mesma não deixa de admitir outros meios de solução de conflitos que podem ser promovidos pela própria sociedade, assim a jurisdição convive com outros métodos privados de resolução de controvérsias (SILVA, 2019).

Como formas de solução de litígios, tem-se a autotutela sendo aplicada desde os primórdios da sociedade, os meios heterocompositivos e autocompositivos. No método heterocompositivo a solução do conflito será imposta por um terceiro, juiz ou árbitro, submetendo as partes a essa decisão mesmo que não satisfaça aos seus interesses, enquanto no método autocompositivo, poderá haver participação de um terceiro para facilitar a comunicação, contudo o resultado depende da vontade dos envolvidos, já que a aceitação ou recusa do acordo depende da escolha dos interessados (CAHALI, 2018).

Esses sistemas, oferecem às partes a escolha dos métodos que melhor se adéqua às suas necessidades, utilizando mecanismos privados e informais para resolver em conjunto os conflitos, surgindo assim o que se denomina de justiça multiportas (SILVA, 2019).

Essa ideia de Tribunal Multiportas foi consolidada com a Resolução 125/2010 do $\mathrm{CNJ}$, onde o Estado disponibiliza a sociedade meios alternativos para solucionar seus conflitos, principalmente por meios consensuais, visando a pacificação, essa nova política pública de tratamento adequado dos conflitos de interesses provocou uma mudança na chamada "cultura do litígio", pois as partes envolvidas ajudam na formação de opiniões, e os beneficiários da solução consensual, podem compartilhar 
essa experiencia positiva para ampliação da utilização de tais institutos, com isso, a Resolução possibilitou o desenvolvimento da conciliação e da mediação (CAHALI, 2018).

Conforme pontua Fernanda Tartuce,

O sistema multiportas estatal pode ser definido como a atividade do Poder Judiciário empreendida para orientar os litigantes sobre as diferentes alternativas para compor o conflito, sugerindo qual seria a saída mais pertinente para o deslinde da questão; o Estado se incumbe de encaminhar as partes no sistema de multiportas de forma gratuita, orientando-as antes do início de uma demanda judicial (TARTUCE, 2018, p.72).

Observa-se que o Estado tem o papel de promover e incentivar a utilização de mecanismos adequados de solução de controvérsias, disponibilizando meios que melhor se adéquem as necessidades dos envolvidos, visando o restabelecimento da comunicação e preservação das relações entre as partes, efetivando a pacificação social.

Para o efetivo acesso à justiça é essencial que haja reformas jurídicas, assegurando interesses que não são representados de forma adequada, pois essas novas ondas de reformas atingem tanto a esfera judicial quanto a extrajudicial, alterando a forma dos procedimentos, mudanças estruturais nos tribunais, com participação de terceiros leigos, criação de mecanismos privados e informais de solução de litígios, ocorrendo uma adaptação processual conforme o conflito, envolvendo pessoas, instituições e procedimentos que em conjunto podem resolver ou prevenir diligências. Essa necessidade de se efetivar métodos que realmente satisfaçam os novos direitos, fez surgir reflexões sobre o sistema de prestação jurisdicional (CAPPELLETI; GARTH, 2015).

Assim, o termo meio alternativo de solução de conflitos (MASCs), vem do inglês alternative dispute resolution (ADR), representando os métodos disponíveis às partes para a resolução de suas disputas, mecanismos que diferem do julgamento de um processo judicial, com procedimentos menos informais e a possibilidade de as partes resolverem seus conflitos em conjunto. Há cerca de três décadas, esses métodos foram incorporados no sistema jurídico por todo o mundo, já no Brasil sua 
aplicação é recente, ao contrário da experiência norte-americana. No entanto, a fundamentação para aplicação desses institutos é semelhante, pois os custos e demora da jurisdição estatal conduziram à insatisfação dos litigantes, fazendo com que outros procedimentos, como arbitragem privada, a conciliação e a mediação fossem adotadas (SILVA, 2019).

Além dessas formas de resolução de conflitos, existem outras formas menos utilizadas que podem ser adequadas às circunstâncias de determinados conflitos, como sistema Mini-trial onde as partes podem eleger um representante para cada um dos envolvidos, esses representantes em conjunto indicarão o terceiro para analisar e decidir as questões do conflito e representarão os interesses desses que os indicaram; há o sistema de avalição de terceiro neutro, de comum acordo as partes o indicarão, este possuindo experiência e conhecimento técnico da matéria em conflito para avaliar e dar um diagnóstico a respeito das possíveis hipóteses de êxito que cada parte possui, ou seja, não é uma decisão vinculativa (CAHALI, 2018).

Também há o sistema denominado dispute board, em que é formado um comitê de especialistas independentes que acompanharão a execução de um contrato de longa duração, sempre que necessário haverá reuniões para verificar o cumprimento contratual e quando surgirem eventuais conflitos, as decisões têm caráter de recomendação no qual as partes assumem o compromisso de cumpri-las (CAHALI, 2018).

Sistema esse utilizado principalmente em contratos de construção, pois temporalmente entre a assinatura do contrato até a sua conclusão surgem vários empasses, o uso dessa ferramenta proporciona aos contratantes e contratados resolverem seus conflitos de forma célere e com menor custo financeiro (SALLA, 2019).

Há também o sistema de manejo de conflitos ou também conhecido como design de sistema de disputas (DSD), tem por objetivo gerenciar o conflito com proporções subjetivas, analisando o conflito e verificando qual o melhor método se enquadra para a sua solução, com acompanhamento de facilitadores experientes que 
promoverão a negociação direta, conciliação, mediação e outras técnicas que permita a comunicação e a construção em conjunto de uma solução (CAHALI, 2018).

Para que esse sistema tenha sucesso, será necessário identificar as partes e o interesse de cada uma delas, fazendo um levantamento de suas preocupações, medos, desejos e vontades como também de sua situação econômica e quais as alternativas teriam para participar desse procedimento, considerando o relacionamento entre os envolvidos, objetivando a real satisfação dos interessados (FALECK, 2020).

Outra forma de solução é o Sistema Administrativo de Conflitos de internet (SACl$\mathrm{Adm}$ ), instituído pelo Comitê Gestor de Internet (CGl), com regulamento próprio, dispõe que o "Sistema Administrativo de Conflitos de Internet relativos a nomes de domínios sob o ".br" - SACI-Adm - tem por objetivo a solução de litígios entre o titular de nome de domínio no ".br" (denominado "Titular") e qualquer terceiro (denominado "Reclamante") que conteste a legitimidade do registro do nome de domínio feito pelo Titular". Sendo o conflito resolvido em uma instituição credenciada escolhida pelo reclamante (REGULAMENTO SACI-ADM, 2010).

Esses sistemas desde que, legitimados pelo Estado, oferecem opções que considerarão os interesses dos envolvidos que escolherão o meio de resolução adequado a ser utilizado, representando assim várias portas que podem ser abertas e trilhadas. Esse modelo de multiportas dispõe de diversas formas que podem ser adotadas para a resolução do conflito, possibilita inclusiva a aplicação desse sistema em questões que envolvam Poder Público e as suas Organizações (MARETTI, 2020).

Assim, estão disponíveis métodos que podem ser adequados para a resolução de conflitos de forma eficaz, satisfazendo ambas as partes, em busca da pacificação social e a efetiva solução ferramentas estas que diferem uma da outra, podendo ser aplicada conforme a necessidade das partes, acolhendo as peculiaridades de cada 
conflito. Os métodos mais conhecidos e utilizados atualmente é a arbitragem, negociação, mediação e conciliação.

\section{CONCILIAÇÃO, MEDIAÇÃO, NEGOCIAÇÃO E ARBITRAGEM}

No processo autocompositivo as partes em conjunto construirão a resolução de seus conflitos com ajuda ou não de um terceiro, na tentativa de resolver os conflitos. Enquanto na heterocomposição haverá uma decisão seja pelo árbitro ou juiz, onde as partes se submeterão a essa decisão mesmo que não atenda todas as suas necessidades. Como métodos autocompositivos temos a conciliação, mediação e a negociação.

A negociação pode ser entendida como um ato ou uma arte de negociar, objetivando um acordo entre as partes em relação à questão geradora do conflito, sua principal característica está no diálogo desenvolvido entre as partes, voltado a uma solução amistosa dos problemas entre elas, sem que ocorra a interferência de um terceiro para impor uma decisão (FIGUEIRA JUNIOR, 2019).

Nesse sistema as partes tendem a resolver de forma direta suas divergências, negociando trocas de vantagens e diminuição de perdas visando o resultado de ganhos recíprocos aceitáveis por ambas as partes, em regra a negociação será exercida pelos próprios interessados, mas não há impedimentos, podendo ser realizada por um terceiro, o negociador, que representará o interesse da parte que 0 nomeou, podendo negociar a melhor solução para seu representante, a figura do negociador está ganhando grandes proporções no mundo dos negócios (CAHALI, 2018).

A busca pela resolução consensual dos conflitos se faz crescente, em vista de seus benefícios. A negociação como meio consensual de resolução tem sido bem valorizada no ordenamento jurídico brasileiro (MARCATO; TARTUCE, 2018).

A conciliação pode ser entendida como um processo em que um terceiro imparcial, ouvira as opiniões e os anseios de cada parte e a partir dessas informações auxiliará 
na solução do conflito, dando sugestões, sugerindo propostas que atendam a vontade dos interessados ensejando a finalização do processo (BARCELLAR, 2012).

Diferentemente da negociação, na conciliação e na mediação haverá a participação de um terceiro facilitador e imparcial que auxiliará as partes a encontrarem a melhor solução para seus empasses.

A conciliação é recomendada para resolução de controvérsias onde as partes não possuam vínculos anteriores, pois seu objetivo é solucionar o conflito e não reestabelecer ou preservar relações. Historicamente a conciliação está interligada com o judiciário, por meio da sua aplicação no curso do processo, em que o magistrado promoverá a tentativa de conciliação em uma audiência própria para este fim (CAHALI, 2018).

Assim dispõe o Código de Processo Civil, sobre os meios consensuais, no seu Art. $3^{\circ}, \S 2^{\circ}$ "O Estado promoverá, sempre que possível, a solução consensual dos conflitos" e no seu $\S 3^{\circ}$ "A conciliação, a mediação e outros métodos de solução consensual de conflitos deverão ser estimulados por juízes, advogados, defensores públicos e membros do Ministério Público, inclusive no curso do processo judicial". Também, trouxe no art. 165, do mesmo diploma legal, a determinação de criação de centros judiciários de solução consensual de conflitos (CEJUSCs), pelos tribunais onde ocorrerão as audiências estimulando assim a autocomposição (BRASIL, 2015).

A mediação diferentemente da conciliação, procura resolver o conflito pacificamente com auxílio de um terceiro neutro que intermediará o retorno da comunicação entre as partes, visando a manutenção e preservação da relação entre as partes (BARCELLAR, 2012).

Assim, tem-se a diferenciação de tais institutos, promovida por Luciano Souto Dias e Kamila Cardoso Faria:

Apesar de serem institutos parecidos, a mediação e a conciliação se diferem em aspectos relevantes. Como métodos de solução consensual de conflitos, 
elas permitem que os interessados dialoguem e que, juntos possam encontrar a melhor solução do conflito, sem a necessidade da imposição de uma decisão por um terceiro. Tanto na mediação quanto na conciliação, tem-se a figura de um terceiro, imparcial, com a função de auxiliar os envolvidos, aquém não cabe resolver o problema, mas exercer um papel de incentivador da solução do conflito. O conciliador tem um papel mais ativo, pois além de conduzir o diálogo, apresenta propostas e sugestões para a solução do conflito. Já o mediador tem uma atuação mais reservada, abstendo-se de propostas ou sugestões, porém, através do seu conhecimento técnico, acompanha o diálogo e atua no sentido de esclarecer aspectos inerentes às questões litigiosas que podem colaborar para que as partes alcancem um consenso (DIAS; FARIA, 2016, p. 27).

A mediação faz parte dos métodos autocompositivos de natureza voluntaria, conforme preceitua a professora Fernanda Tartuce:

A mediação consiste no meio consensual de abordagem de controvérsias em que alguém imparcial atua para facilitar a comunicação entre os envolvidos e propiciar que eles possam, a partir da percepção ampliada dos meandros da situação controvertida, protagonizar saídas produtivas para os impasses que os envolvem (TARTUCE, 2018, p. 203).

Portanto, neste método de solução de conflito, haverá a participação de um terceiro que seja capacitado com conhecimentos específicos em relação à matéria que está sendo discutida, usando técnicas para reestabelecer a comunicação perdida em decorrência do desentendimento, e auxiliando os interessados formularem a solução para os seus conflitos.

A mediação tem o objetivo de promover e facilitar a comunicação dos conflitantes, sendo que os interessados podem escolher esse meio de solução, pois mesmo que não haja a celebração do acordo, a mediação será bem-sucedida se a comunicação entre os envolvidos for retomada (TARTUCE, 2018).

Em vista da crise no judiciário vivenciada na sociedade contemporânea, a mediação tem ganhado grandes proporções, passando a ser estudada no mundo jurídico, seminários e palestras apresentados sobre o tema, surgindo normas para regularização de tal instituto, como marco legal tem-se a Resolução 125/2010 do Conselho Nacional de Justiça, e a valoração trazida pelo Código de Processo Civil de 2015, bem como a promulgação da Lei de Mediação no 13.140 de 2015 (BERTOLI; BUSNELLO, 2017). 
Com a promulgação da Lei 13.140 de 2015 , a aplicação da mediação foi regulada, dispondo de regras e procedimentos para a realização e aplicação da mediação entre particulares, bem como conflitos que envolvam a administração pública (MERETTI, 2020).

Com isso conclui-se que a mediação é um instituto que pode se enquadrar aos conflitos, desde que haja a voluntariedade das partes e a lei permita a utilização desse instrumento, podendo resolver tanto controvérsias entre particulares, como os conflitos que envolvam particular e a administração pública.

A lei em comento, preceitua regras que disciplinam a adoção da mediação tanto na seara judicial, quanto na extrajudicial, que envolvam direitos disponíveis ou indisponíveis desde que transigíveis, podendo tratar de partes ou de todo o conflito, como também trouxe o conceito de mediação no seu art. $1^{\circ}$, "Parágrafo único: Considera-se mediação a atividade técnica exercida por terceiro imparcial sem poder decisório, que, escolhido ou aceito pelas partes, as auxilia e estimula a identificar ou desenvolver soluções consensuais para a controvérsia." Assim, a mediação está se desenvolvendo como método capaz de fazer com as pessoas resolvam seus problemas, por vontade própria, com auxílio de um terceiro, aumentando assim o grau de satisfação, pois a solução foi construída por elas mesmo, pois a resolução do conflito se torna mais eficaz e ocorre em menos tempo, beneficiando todos os envolvidos (BERTOLI; BUSNELLO, 2017).

Já a arbitragem é uma forma de solução impositiva, fazendo parte do método heterocompositivo, sendo que a solução do conflito se dará por uma decisão elaborada por terceiro ou por uma câmara arbitral. $\mathrm{Na}$ arbitragem as partes podem escolher uma ou mais pessoas através de uma convenção privada, que decidirão a controvérsia, essa decisão terá força de sentença judicial, e está disponível para qualquer pessoa capaz, desde que os conflitos sejam relacionados a direitos patrimoniais disponíveis (CARMONA, 2009).

Como bem esclarece Alexandre Freitas Câmera: 
A arbitragem é um processo paraestatal e heterocompositivo de solução de conflitos, há que se verificar quando sua utilização é cabível. Afirma a lei de arbitragem que esta pode ser usada por pessoas capazes quando o conflito versar sobre direitos patrimoniais disponíveis (art.1ํ). Há que se dizer, assim, que tanto as pessoas jurídicas como as pessoas naturais e capazes podem se valer da arbitragem como meio de solução de litígios (CÂMERA, 2005, p. 178).

A arbitragem é um importante instrumento de resolução de conflitos, que está à disposição daqueles que a escolherem para resolver conflitos que envolvam questões patrimoniais, sendo que a resolução se dará por uma decisão proferida por um terceiro imparcial, tanto pessoas físicas quanto jurídicas podem se valer desse instrumento.

Em 1996, a arbitragem ganhou sua própria regulação, com a Lei nำ 9.307, uma verdadeira revolução jurídica para o Brasil em relação à arbitragem, com essa lei o instituto ganhou mais segurança jurídica, afastando alguns empecilhos que impediam seu desenvolvimento, pois com advento da lei citada, a cláusula compromissória passa a ter caráter obrigatório, e a decisão arbitral não mais necessita de homologação judicial, assim permitindo o avanço da arbitragem no País (BARCELLAR, 2012).

A Lei 13.129 de 2015, alterou alguns dispositivos da Lei $n^{0}$ 9.307/96, sendo que uma dessas novidades, foi a permissão da utilização da arbitragem por órgãos da administração pública direta e indireta, ampliando o campo de atuação da arbitragem. Embora se tenha ampliado a aplicação desse método de resolução ainda é restrita a um certo grupo de litigantes, em decorrência dos altos custos (SILVA, 2019).

A arbitragem, a negociação, a conciliação, a mediação entre outros, estão se desenvolvendo, pois, os benefícios decorrentes desses métodos são evidentes, bem como a insatisfação da população com o judiciário, que estão cada vez mais em busca de soluções mais eficazes, céleres e satisfaça todos os envolvidos. Percebese o avanço na utilização desses métodos de resolução, o que é inclusive, bem recomendada por parte da doutrina brasileira, pois algumas experiências bemsucedidas comprovam a efetividade desses métodos. 


\section{MEDIAÇÃO E SUAS PARTICULARIDADES}

A mediação privada, é um procedimento muito utilizado internacionalmente, principalmente na resolução de conflitos comerciais (ISOLDI, 2014).

Tendo seu desenvolvimento acentuado com a sua regulação elaborada pela United Nations Commissionson International Trade Law (UNCITRAL), a "Lei Modelo", Model Law on International Commercial Conciliation de 2002, servindo de modelo para elaboração de outras normas que tratarem do mesmo assunto (UNCITROL, 2002).

No Brasil a mediação passou a ter uma atenção maior, com a criação do Instituto Nacional de Mediação e Arbitragem (INAMA) em 1991, impulsionando seu estudo por vários institutos, e no ano de 1994, foi criado o Instituto da Mediação (IM), que em 1997, foi intitulado como Instituto da Mediação e Arbitragem do Brasil (IMAB). Neste mesmo ano foi criado o Conselho Nacional das Instituições de Mediação e Arbitragem (COMINA). A iniciativa de normatização do tema ocorreu em 1998 (por força do Projeto de Lei 4.827/98, de autoria da Deputada Zulaiê Cobra). E no ano de 2010, foi publicado a Resolução CNJ no 125, objetivando a aplicação dos meios adequados de resolução de conflitos no judiciário bem como os parâmetros de capacitação e prática dos conciliadores e mediadores judiciais. Contudo, a mediação ganhou sua própria norma em 2015, com a promulgação da Lei de Mediação no 13.140, no Congresso Nacional (BRAGA NETO, 2019).

Outro ponto importante que alavanca o desenvolvimento da mediação é a convenção de Singapura, com 53 países signatários, visa unificar a prática da mediação internacional, e facilitar os acordos resultantes das mediações empresariais no âmbito internacional. O Brasil assinou a convenção recentemente, em 4 de junho de 2021, proporcionando grandes expectativas para ampliação da mediação no país (MINISTERIO ECONOMIA, 2021).

Com advento da Lei de Mediação no 13.140/2015, regularizou-se o procedimento de aplicação da mediação tanto na esfera judicial como na extrajudicial, também 
especificando o objeto que pode ser matéria da mediação, e os princípios aplicados ao instituto.

\subsection{PRINCÍPIOS DA MEDIAÇÃO}

Sobre os princípios da mediação a Lei $n^{\circ}$ 13.140/2015, dispõe em seu Art. 2o A mediação será orientada pelos seguintes princípios: I - imparcialidade do mediador; II - isonomia entre as partes; III - oralidade; IV - informalidade; V - autonomia da vontade das partes; VI - busca do consenso; VII - confidencialidade; VIII - boa-fé (BRASIL, 2015).

O primeiro princípio refere-se à imparcialidade do mediador, essencial para o justo tratamento das partes, pois todos os atos desse terceiro convidado para auxiliar na resolução do conflito devem ser equânimes, sendo inclusive submetidos as normas de impedimentos e suspeição aplicados aos magistrados, por equiparação. $O$ princípio da Autonomia da vontade das partes é um dos mais importantes, pois reconhece à vontade, liberdade e a decisão das partes, bem como a voluntariedade dos mesmos em aceitar e participar do processo de mediação. A mediação é pautada no princípio da busca do consenso e da cooperação entre as partes, pois reestabelece a comunicação entre ambos, estimulando as partes a construírem sua própria solução (TARTUCE, 2018).

Já o princípio da informalidade coordena todo o procedimento da mediação que se desenvolve para promover o diálogo, com técnicas informais para que a comunicação se desenvolva com tranquilidade. Por se pautado no reestabelecimento da comunicação é evidente o princípio da oralidade em todas as fases da mediação. O princípio da boa-fé refere-se à participação das partes de forma leal, com comprometimento e respeito mútuo, como também deve ser proporcionado oportunidades iguais às partes (TARTUCE, 2018).

O princípio da confidencialidade cobre todos os atos na mediação, um dos atrativos para empresas se valerem desse método. Sendo muito importante para que as partes se sintam confortáveis, e todos os atos em relação às informações prestadas 
pelas partes, fatos, relatos e documentos que fizerem parte do processo de mediação, serão sigilosos. Sendo inclusive vedado o mediador servir como testemunha, salvo se as partes autorizarem. Tamanha a importância da confidencialidade, que a Lei de Mediação dispôs de uma seção própria para tratar o tema (CAHALI, 2018).

Percebe-se que a mediação tem suas peculiaridades e pode proporcionar àqueles que procuram um procedimento para solucionar os empasses que surgirem no decorrer de relações contratuais, de forma eficaz, com celeridade, e sigilo. Podendo ser indicado inclusive para prevenção de conflitos empresariais, por meio do diálogo promovendo um ambiente de pacificação, estabelecendo a comunicação e a preservação das relações comerciais.

\subsection{MEDIAÇÃO EMPRESARIAL}

Há duas formas de mediação, a judicial e a extrajudicial. Assim, tratar-se-á da medição extrajudicial, também conhecida como mediação privada.

A mediação privada aplicada nas controvérsias que envolvam atividade empresarial não se resume só a solução dos conflitos, mas em reestabelecer a comunicação entre os envolvidos mantendo assim a relação e continuação do contrato.

A mediação extrajudicial, se dará por meio da vontade das partes em optar pela aplicação de tal instituto, onde poderão escolher o mediador, a forma como ocorrerá a mediação, bem como definir qual será o objeto da controvérsia e se tratou de todo ou parte do conflito, por meio do estabelecimento de uma cláusula de mediação (BRANDÃO, 2019).

No contexto Empresarial, Diego Faleck assim define a mediação:

A mediação empresarial consiste na facilitação, por um terceiro neutro, de negociação para a resolução de disputa, entre partes de relações comerciais. Mediadores não têm o poder de impor uma decisão vinculante. Todavia, a intervenção de mediadores é extremamente eficaz para assistir partes a resolverem disputas em menor tempo, com menor gasto de recursos e com maior preservação de relacionamentos comerciais (FALECK, 2014, p. 263). 
A Lei Modelo de Mediação, trouxe em seu texto, especificações sobre a aplicação do instituto para resolução de conflitos comerciais, expressão esta não se limita a atividade comercial, mas abrangendo qualquer atividade empresarial relacionada a natureza comercial, contratual ou não, objetivando a simplificação da negociação nos conflitos comerciais (BRANDÃO, 2019).

Nesse sentido, nota-se que a mediação tem natureza jurídica contratual, pois através da vontade das partes, estipulam por contrato a intervenção de um terceiro que Ihes auxiliaram a retomar o diálogo (BRAGA NETO, 2019).

A escolha do mediador fica a critério das partes, contudo indica-se que tenha conhecimentos técnicos da matéria em conflito, pois o mediador é o facilitador da comunicação e vai conduzir o procedimento de forma imparcial, assegurando a participação equilibrada entre as partes, estimulando os participantes a vencer as barreiras que impeçam o acordo, sempre prestando os esclarecimentos necessários de forma clara acerca do procedimento (BRANDÃO, 2019).

A lei de mediação deixa claro que a participação de advogado é facultativa, conforme art. 10 da lei de mediação. Mas a participação do advogado pode ser importante, ao orientar juridicamente o cliente ou no caso de efetuado o acordo, poderá auxiliar na redação do instrumento, e no caso de não haver acordo, orientará as medidas necessárias que resguardem os interesses de seu cliente.

Assim, a Lei oㅜ 13.140/2015, dispõe no art. 21 e seguintes como ocorrerá todo o procedimento da mediação extrajudicial, podendo ser iniciada por contrato ou iniciativa direta de uma das partes.

\subsection{APLICAÇÃO E DESENVOLVIMENTO DA MEDIAÇÃO EMPRESARIAL}

Conforme disposição em lei a mediação privada pode se iniciar tanto com a cláusula ou sem cláusula de mediação. É o que se observa no art. 22 da Lei de Mediação, que dispõe sobre a cláusula de mediação, estabelecida por contrato devendo conter 
prazo, local, como será feita a escolha dos mediadores e possíveis penalidades, esse contrato terá um efeito vinculante entre as partes (CAHALI, 2018).

Neste contrato poderá ser estabelecido a cláusula autônoma, ou escalonada ou com uso de mixed-modes em que os interessados poderão combinar estipulações sequenciadas dos métodos adequados de resolução de conflitos neg-med-arbit ou med-arb, med-jud ou neg-med-jud (SIMÕES, 2019).

Já sem a cláusula de mediação prévia, o Art. 16 da Lei de Mediação, dispõe que as partes podem requerer a suspensão do processo caso em que já instaurada a lide, por um período suficiente para que ocorra a mediação, ou poderá fazer o convite à outra parte, promovido por qualquer meio de comunicação descrevendo objeto de negociação, local, e data da reunião (BRASIL, 2015).

Desse modo, a mediação poderá ser promovida pela via institucional, onde as partes escolhem uma câmera ou centro de mediação, submetendo-se a suas regras administrativas da organização, ou poderá ser instituído por via independente, "ad hoc", sendo que as regras do procedimento da mediação serão estipuladas pelas próprias partes (ROSA; ISSA, 2019).

O processo de mediação pode ocorrer em algumas etapas, na primeira etapa ocorre apresentação das informações sobre as regras e detalhes de como ocorrerá todo o procedimento e o mediador atesta a sua independência, podendo ser chamada prémediação. Na segunda etapa há o relato das partes, e a compreensão das expectativas de cada envolvido, podendo ser designadas reuniões privados ou individuais (caucus), ferramenta está utilizada para ampliar a visão relativa do conflito; na terceira etapa o mediador estimulara as partes quanto as possibilidades de soluções do conflito, desenvolvimento de propostas e negociações. Por último é a realização do acordo se este for efetivado, devendo ser redigido a termo com todos os compromissos assumidos, com assinatura dos envolvidos (TARTUCE, 2012).

A mediação tem se tornado um instrumento muito importante para preservar relações principalmente no campo empresarial, todo o procedimento com etapas 
que proporcionam as partes exporem suas ideias, a exercerem sua autonomia, sobre o manto da confidencialidade e necessitam manter a relação contratual para o cumprimento de alguma obrigação, bem como a preservação da imagem da empresa no mercado. Algumas experiências empresariais que se valeram da mediação foram bem-sucedidas comprovam os benefícios e a eficácia da mediação empresarial.

\section{A MEDIAÇÃO, SERIA ADEQUADA E BENÉfICA PARA RESOLVER CONFLITOS EMPRESARIAIS?}

Nos conflitos empresariais, é possível se valer dos métodos extrajudiciais de solução de conflitos, desde que haja voluntariedade, bem como a possibilidade de se aplicar tais métodos, em vista da peculiaridade de cada conflito, e o que dispõe a lei sobre a aplicação de cada instituto ao caso concreto.

Os conflitos empresariais, por envolver um histórico de inter-relação entres os envolvidos, recomenda-se o uso da mediação, que possibilita o reestabelecimento da convivência harmônica e a preservação das relações entre os sócios quando surgirem sinais de divergências, antes mesmo do conflito ser instaurado, assim a mediação terá a função de prevenir conflitos. Como, pode ser utilizada para a pacificação, quando já instaurados os conflitos empresariais (CAHALI, 2018).

Observa-se que a mediação poderá ser aplicada antes do conflito instaurado, como na sua ocorrência, buscando não só a solução do conflito, como também a continuidade e manutenção das relações empresariais.

O artigo $3^{\circ}$ da Lei de Mediação dispõe que poderá ser objeto de mediação o conflito que verse sobre direitos disponíveis ou sobre direitos indisponíveis que admitam transação.

Os conflitos corriqueiros enfrentados pelas empresas, podem ser internos ou externa corporis, decorrentes das relações comerciais ou administrativas, contratos de propriedade intelectual, execução de uma obra, relações franqueado e franqueador, 
e até mesmo de relacionamentos em empresas familiares, entre outros vínculos decorrentes da atividade empresarial (BRAGA NETO, 2019).

Os conflitos podem surgir tanto, na própria empresa como na relação com terceiros, a doutrina classifica esses conflitos, se derivados de assuntos corporativos internos, como intraorganizacional ou intraempresarial (BRAGA NETO, 2015).

Nesse contexto a mediação será destinada a solucionar disputas entre funcionários, departamentos, diretoria, diretores e sócios, entre si, a empresa poderá usar serviços de câmeras de mediação especializados ou treinar sua própria equipe, porém aconselha-se a busca por mediadores imparciais para tratamento isonômica das partes (FREIRE; BRAGA NETO, 2019).

Assim, a mediação organizacional, também pode ser chamada mediação corporativa, que visa o reestabelecimento das relações internas, pois se a relação entre os colaboradores não estiverem bem poderá influenciar negativamente na imagem externa da empresa, impedindo assim o alcance dos objetivos que a mesma almeja (SIMÕES, 2019).

Essa prática no ambiente corporativo pode se relacionar com a implementação do programa de compliance, cujo objetivo é desenvolver políticas organizacionais e códigos de conduta, mudando a cultura interna da empresa tornando-a mais íntegra e transparente, em busca da preservação da empresa (FREIRE; BRAGA NETO, 2019).

Nota-se atualmente a preocupação com a integridade e a imagem que a empresa transmite ao mundo exterior, e a mediação pode ser uma ferramenta a ser utilizada para preservar a imagem da empresa.

Já nas relações empresariais externas, pode ser denominada mediação interempresarial, onde 0 mediador trabalhará elementos de reflexão e questionamentos da inter-relação existentes entre os empresários, construindo 
assim uma solução pacífica, como também restabelecer a comunicação entre as partes, e a manutenção dessa relação (BRAGA NETO, 2015).

$\mathrm{Na}$ recuperação de empresas a mediação pode ser aplicada tanto no sistema de recuperação judicial como no extrajudicial, sendo inclusive estimulado o uso da conciliação e mediação pela Lei 14.112 de 2020, que trouxe significativas mudanças na Lei de 11.101/05, com uma seção própria Seção, Das conciliações e das mediações antecedentes ou incidentais aos processos de recuperação judicial, portanto a mediação poderá ser aplicada antes do processo de recuperação ou no curso do processo, também há possibilidade de aplica-la nos processos que estão com recursos nos Tribunais Superiores, vale mencionar que instaurada a mediação os prazos determinados pela lei não serão suspensos, exceto por determinação do juiz, ou convencionado pelas partes (FERNANDES, 2021).

Contudo, a lei traz duas vedações ao uso da mediação no $\S 2^{\circ}$ do art. 20-B: São vedadas a conciliação e a mediação sobre a natureza jurídica e a classificação de créditos, bem como sobre critérios de votação em assembleia-geral de credores. Outra novidade trazida pelo artigo 20-D, do mesmo diploma legal foi possibilidade da realização da mediação em plataformas digitais. O que se mostra adequado em vista do momento vivenciado no país, em razão da pandemia (BRASIL, 2015).

Há também a recomendação № 58 do CNJ de 22 de outubro de 2019:

Art. 1ํ Recomendar a todos os magistrados responsáveis pelo processamento e julgamento dos processos de recuperação empresarial e falências, de varas especializadas ou não, que promovam, sempre que possível, nos termos da Lei no $13.105 / 2015$ e da Lei no $13.140 / 2015$, o uso da mediação, de forma a auxiliar a resolução de todo e qualquer conflito entre o empresário/sociedade, em recuperação ou falidos, e seus credores, fornecedores, sócios, acionistas e terceiros interessados no processo (CONSELHO NACIONAL DE JUSTIÇA, 2019).

A aplicação da mediação na recuperação de empresas trará celeridade na formação do quadro de credores e eficiência na negociação do plano de recuperação, e com excelentes resultados (FERNANDES, 2021). 
A aplicação da mediação na esfera comercial pode ser uma ótima opção para evitar, enfrentar ou solucionar as desavenças empresariais, sendo que as partes vão dialogar com o mediador, um terceiro qualificado, sobre interesses e necessidades de cada interessado, para construir a melhor solução do conflito, e no menor tempo do que teriam se recorressem ao judiciário, já que nessa seara tempo é dinheiro, a mediação pode resolver os conflitos de forma eficaz e em menos tempo (SIMÕES, 2019).

Um bom exemplo, foi a aplicação da mediação no acidente de consumo, em um programa de indenização, inclusive há câmeras extrajudiciais de indenização no Brasil, criadas em decorrência de acidentes aéreos ocorridos em 2007 e 2009, os programas foram criados pelo Ministério da Justiça por influência de Diego Faleck, secretário de desenvolvimento econômico, o programa foi pautado na autonomia das partes, favorecendo a comunicação entre as empresas e familiares das vítimas. O programa de indenização por meio da mediação foi um sucesso, servindo de parâmetros para a ampliação da aplicabilidade da mediação (TARTUCE, 2012).

Uma experiência bem sucedida, foi o programa de indenização 447, composto pela Société Air France (Air France), suas seguradoras (representadas pela seguradora líder, AXA Corporate Solutions - AXA) e por órgãos do Sistema Nacional de Defesa do Consumidor: Ministério Público do Estado do Rio de Janeiro (MPE/RJ), Fundação Procon/RJ (PROCON/RJ) e Secretaria de Direito Econômico do Ministério da Justiça (SDE/MJ), e os familiares das vítimas do acidente aéreo, ocorrido em 30 de maio de 2009, no voo 447 Rio-Paris. Com participação de três mediadoras, foram elaborados o regimento interno com regras e princípios, e o manual de orientação aos participantes, enviado cartas-convite para os familiares participarem da abertura do programa, ao todo cerca de 70 pessoas participaram e receberam a indenização. Em primeiro momento as mediadoras prestavam todos os esclarecimentos e explicavam sobre o programa, após a adesão ao programa pelos familiares avaliouse a legitimidade dos beneficiários e a provas necessárias, todas as dúvidas foram esclarecidas pelos envolvidos por meio da comunicação, ocorrendo tanto reuniões privadas como reuniões em conjunto, após elaborada proposta teve-se a reunião 
final com a aceitação e assinatura do acordo final. Constatando-se a eficiência do processo de mediação, e a satisfação dos envolvidos (TARTUCE, 2012).

Observa-se que a mediação vem sendo estimulada, e de forma tímida ganhando grandes proporções, podendo demonstrar eficiência na resolução de muitas controvérsias em diversas áreas do Direito.

\section{EFICÁCIA DO ACORDO FINAL DA MEDIAÇÃO}

$\mathrm{Na}$ hipótese de celebração de acordo, no procedimento da mediação privada, o termo final constitui-se em um documento escrito e assinado pelas partes com força de título executivo extrajudicial, caso, não houver o cumprimento espontâneo, o título poderá ser executado judicialmente forçando a parte resistente a cumprir os termos acordados.

Assim a Lei $n^{\circ} 13.140 / 2015$, bem específica:

Art. 20. O procedimento de mediação será encerrado com a lavratura do seu termo final, quando for celebrado acordo ou quando não se justificarem novos esforços para a obtenção de consenso, seja por declaração do mediador nesse sentido ou por manifestação de qualquer das partes. Parágrafo único. O termo final de mediação, na hipótese de celebração de acordo, constitui título executivo extrajudicial e, quando homologado judicialmente, título executivo judicial (BRASIL, 2015).

O termo final da mediação ao ter força de título executivo extrajudicial, promove uma segurança quanto ao possível descumprimento do termo. Contudo, pode se dizer que há um alto grau de cumprimento dos acordos feitos no procedimento da mediação, pois às próprias partes é quem resolvem e constroem a solução do conflito de forma conjunta, elaborando os próprios termos. Assim há um maior adimplemento, pois o objetivo da mediação é fazer com que as partes encontrem a melhor solução para o problema que Ihes aflige. Fazendo com que ambos saiam satisfeitos com o acordo o que aumenta o cumprimento espontâneo do acordo. 


\section{DESAFIOS DA MEDIAÇÃO EMPRESARIAL NO BRASIL}

O primeiro desafio enfrentado pela mediação é a busca pela mudança cultural brasileira, pois a judicialização dos conflitos é a regra, já que a utilização da via judicial para solução de conflitos perdura por anos. Não será fácil mudar essa cultura, mas gradualmente a busca por meios alternativos tem se intensificado em vista da crise do judiciário. Outro desafio é o desconhecimento por parte do mercado, sobre as vantagens e a eficácia do procedimento, há também, a insegurança em se valer do método, outra preocupação está relacionada a preparação dos mediadores para lidar com as especificidades da mediação empresarial, bem como a adequada capacitação e remuneração dos mediadores (FREIRE; BRGA NETO, 2019).

Sendo que há a preocupação de se colocar questões importantes nas mãos de quem não tenha competência para tal, ocasionando um prejuízo maior, assim é importante a qualificação dos mediares na matéria em que atuarão e uma adequada remuneração para esses profissionais que se dedicarão a intermediar a busca pela solução do conflito.

Pode-se dizer, que a sociedade tem como costume se valer da tutela jurisdicional, colocando nas mãos do estado-juiz, a responsabilidade de resolver seus conflitos. Muitas vezes pela segurança da decisão jurisdicional, ou pela necessidade de uma declaração do direito. Contudo, o judiciário não dá conta de satisfazer todos aqueles que o procuram. Assim a mediação pode ser uma ótima opção para estrategicamente alcançar-se a melhor solução.

\section{CONSIDERAÇÕES FINAIS}

Este trabalho teve como objetivo analisar a mediação extrajudicial como método adequado e eficaz na resolução de conflitos empresariais. Demonstrando que a mediação é eficaz, e suas técnicas podem proporcionar as organizações empresariais vantagens como, simplicidade do rito, predominância da informalidade 
e regras mais flexíveis, soluções que realmente satisfaçam todos os envolvidos, economizando tempo e dinheiro.

Ao decorrer da pesquisa e análise dos métodos consensuais de resolução de controvérsias, observa-se que a mediação é adequada para auxiliar no gerenciamento de conflitos empresariais. Sabemos que as empresas sofrem impactos financeiros com a falta de planejamento e com a morosidade do judiciário. Assim, observou-se que a mediação é eficaz para restabelecer, conservar relações, e gerir conflitos internos e externos, permitindo a continuação dessas relações empresariais, o que proporciona a continuidade da atividade comercial, e o seu desenvolvimento econômico e organizacional.

Durante a pesquisa, como explanado, existem conflitos empresariais em que a mediação foi utilizada, e seu resultado foi positivo, todos os envolvidos saíram satisfeitos. Certificando que a mediação é um ótimo instrumento para resolução de controvérsias empresariais, pois visa proporcionar um espaço de diálogo, confiança, criatividade e a identificação de alternativas em situações conflituosas, e a construção pelas próprias partes de acordos sustentáveis, em menor tempo, com maior custo-benefício em relação à arbitragem e o processo judicial que possui custos elevadíssimos. Outro benefício é a confidencialidade, pois todos os atos praticados no processo da mediação serão sigilosos, preservando assim a imagem da empresa.

Nota-se que há uma efetividade maior no adimplemento dos acordos efetuados no termo final da mediação, pois as próprias partes elaborarão a solução do empasse, fazendo com que ambos cumpram suas obrigações, ocorrendo a satisfação mútua.

Por fim, conclui-se que a utilização da mediação é adequada e eficaz para solucionar os empasses empresariais, pois os benefícios e a satisfação, gerados pela utilização do método já foram comprovados com experiências brasileiras. Apesar de existirem alguns desafios na implementação tanto da mediação como de outros métodos de resolução de conflitos, gradualmente estão sendo superados, e o desenvolvimento desses métodos se expandindo ainda que de forma tímida. 


\section{REFERÊNCIAS}

BARCELLAR, Roberto Portugal. Mediação e arbitragem: coleção saberes do direito. São Paulo: Saraiva, 2012. p. 210.

BÉRTOLI, Rubia Fiamoncini; BUSNELLO, Saul José. Métodos heterocompositivos e autocompositivos de solução de conflitos: a Mediação como meio de efetivar a obtenção da Justiça. 2017. Disponível em: https://s3-saeast-1.amazonaws.com/siteunidavi/revistaDireito/Artigo_Saul_R\%C3\%BAbia.pdf. Acesso em: 28 maio 2021.

BRAGA NETO, Adolfo. A mediação de conflitos no contexto empresarial. In: SOUZA, Luciane Moessa de (org.). Mediação de conflitos: novo paradigma de acesso à justiça. Santa Cruz do Sul: Essere Nel Mondo, 2ํed. 2015. p. 159-170.

BRAGA NETO, Adolfo. Mediação: uma experiência brasileira. Editora CLA cultural, 2019, São Paulo.

BRANDÃO, Clésia Domingos. Mediação empresarial: uma análise da aplicabilidade e efetividade do instituto nos conflitos entre empresas. 2019. 159 f. Dissertação (Mestrado em Direito) - Universidade Nove de Julho, São Paulo. Disponível em http://bibliotecatede.uninove.br/handle/tede/2117. Acesso em 20 abr.2021.

CAHALI, Francisco José. Curso de Arbitragem. Mediação. Conciliação. Tribunal Multiportas. 7. ed. São Paulo: Thomson Reuters, 2018. 601 p. Rev. atual. e ampl.

CÂMERA, Alexandre Freitas. Arbitragem Lei no 9.307/96. 4. ed. Rio de Janeiro: Lumen Juris, 2005. 178 p.

CAPPELLETTI, Mauro; GARTH, Bryant. Acesso à justiça. Trad. Ellen Gracie Northfleet. Porto Alegre: Fabris. Reimp. 2015, 168 p.

CARMONA, Carlos Alberto. Arbitragem e Processo. São Paulo: Atlas, 3aㅡ Edição, 2009. P. 592. 
DIAS, Luciano Souto; FARIA, Kamila Cardoso. A mediação e a conciliação no contexto do novo código de processo civil de 2015. Revista Digital Constituição e Garantia de Direitos, v. 8, n. 2, p. 20 - 44, 17 ago. 2016. Disponível em: https://www.periodicos.ufrn.br/constituicaoegarantiadedireitos/article/view/9990. Acesso em: 27 maio 2021.

FALECK, Diego. Mediação empresarial: introdução e aspectos práticos. Revista de Arbitragem e Mediação, São Paulo, v. 11, n. 42, p. 263-278, jul. 2014.

FALECK, Diego. Um passo adiante para resolver problemas complexos: desenho de sistemas de disputas. In: Negociação, mediação, conciliação e arbitragem: curso de métodos adequados de solução de controvérsias / coord. Carlos Alberto de Salles, Marco Antônio Garcia Lopes Lorencini, Paulo Eduardo Alves da Silva. - 3. ed. - Rio de Janeiro: Forense, 2020. P. 108-131.

FERNANDES, Sônia Caetano. A mediação empresarial no novo sistema de recuperação judicial de empresas implementado pela lei 14.112/20. 2021. Disponível em: https://www.migalhas.com.br/depeso/340921/mediacao-empresarialno-sistema-de-recuperacao-judicial-de-empresas. Acesso em: 28 maio 2021.

FIGUEIRA JUNIOR, Joel Dias. Arbitragem. 3. ed. Rio de Janeiro: Forense, 2019. $521 \mathrm{p}$.

FREIRE, Jose Nantala Bádue; BRAGA NETO, Adolfo. Os desafios da mediação empresarial no Brasil. In: BRAGA NETO, Adolfo (org.). Mediação empresarial: experiências brasileiras. São Paulo: CLA Cultural, 2019. p. 15-28. Ebook.

ISOLDI, Ana Luiza (org.). A mediação no âmbito empresarial - um breve estudo acerca de sua definição em instituições nacionais e estrangeiras. 2014. Disponível em: https://pt.scribd.com/document/415947656/GEMEP-CBAr-mediacaoprivada-breve-estudo-docx. Acesso em: 20 abr. 2021.

MARCATO, Ana Cândida Menezes; TARTUCE, Fernanda. Mediação no direito empresarial: possibilidades interessantes em conflitos securitários. 2018. 
Disponível

em:

http://www.fernandatartuce.com.br/wpcontent/uploads/2018/05/Media\%C3\%A7\%C3\%A3o-dir-empresarial-conflitossecuritarios-Ana-Marcato-e-Fernanda-Tartuce.pdf. Acesso em: 02 maio 2021.

MARETTI, Luis Marcello Bessa. Os Desafios no Século XXI para a Resolução de Conflitos e o Uso das Modalidades de Autocomposição como Meios Alternativos. $2020 . \quad$ Disponível em: http://www.enajus.org.br/anais/assets/papers/2020/sessao-11/2-os-desafios-no-seculo-xxi-para-a-resoluc-a-o-de-conflitos-e-o-uso-das-modalidades-de-autocomposica-o-como-meios-alternativos.pdf. Acesso em: 29 maio 2021.

RIOS, Marco Túlio Costa. A mediação nos dissídios trabalhistas individuais e coletivos. Revista Jus Navigandi, ISSN 1518-4862, Teresina, ano 23, n. 5517, 9 ago. 2018. Disponível em: https://jus.com.br/artigos/61030. Acesso em: 20 maio 2021.

ROSA, Beatriz Vidigal Xavier da Silveira; ISSA, Ricardo. Mediação empresarial e engenharia In: BRAGA NETO, Adolfo org.) Mediação empresarial: experiências brasileiras. São Paulo: CLA Cultural, 2019. p. 83-102. Ebook.

SALLA, Ricardo Medina. Aplicação dos Dispute Boards ao Mercado Imobiliário. In: ARAUJO, Paulo Doron R. de (coor.). Arbitragem, Mediação e Dispute Boards no mercado imobiliário. São Paulo: Quartier Latin, 2019. p. 201-211.

SILVA, Paulo Eduardo Alves da. Resolução de disputas: métodos adequados para resultados possíveis e métodos possíveis para resultados adequados. 2019. Disponível em: https://edisciplinas.usp.br/pluginfile.php/4394573/mod_resource/content/1/01 Paulo\%20Eduardo\%20Alves\%20da\%20Silva-2\%C2\%AA\%20Ed.pdf. Acesso em: 26 maio 2021. 
SIMÕES, Alexandre Palermo. Mediação nos conflitos comerciais. In: BRAGA NETO, Adolfo (org.). Mediação empresarial: experiências brasileiras. São Paulo: CLA Cultural, 2019. p. 38-57. Ebook.

TARTUCE, Fernanda. Mediação extrajudicial e indenização por acidente aéreo: relato de uma experiência brasileira. 2012. Disponível em: http://seer.ucp.br/seer/index.php/LexHumana/article/view/211. Acesso em: 20 abr. 2021.

TARTUCE, Fernanda. Mediação nos Conflitos Civil. São Paulo: Método, $4^{\mathrm{a}}$ Edição, 2018.

UNCITRAL Model Law on International Commercial Conciliation (2002), Disponivel em: https://uncitral.un.org/sites/uncitral.un.org/files/media-documents/uncitral/en/0390953_ebook.pdf. Acesso em: 09 maio2021.

Enviado: Julho, 2021.

Aprovado: Dezembro, 2021. 